Supporting information for

\title{
Visualization of Acoustic Energy Absorption in Confined Aqueous Solutions by PNIPAM Microgels: Effects of Bulk Viscosity
}

\section{Amin Rahimzadeh ${ }^{1 *}$, Matthias Rutsch ${ }^{2}$, Mario Kupnik², and Regine von Klitzing ${ }^{1}$}

${ }^{1}$ Department of Physics, Technische Universität Darmstadt, Hochschulstraße 8, 64289 Darmstadt, Germany. ${ }^{2}$ Measurement and Sensor Technology, Technische Universität Darmstadt, Merckstraße 25, 64283 Darmstadt, Germany.

* Corresponding author: rahimzadeh@fkp.tu-darmstadt.de

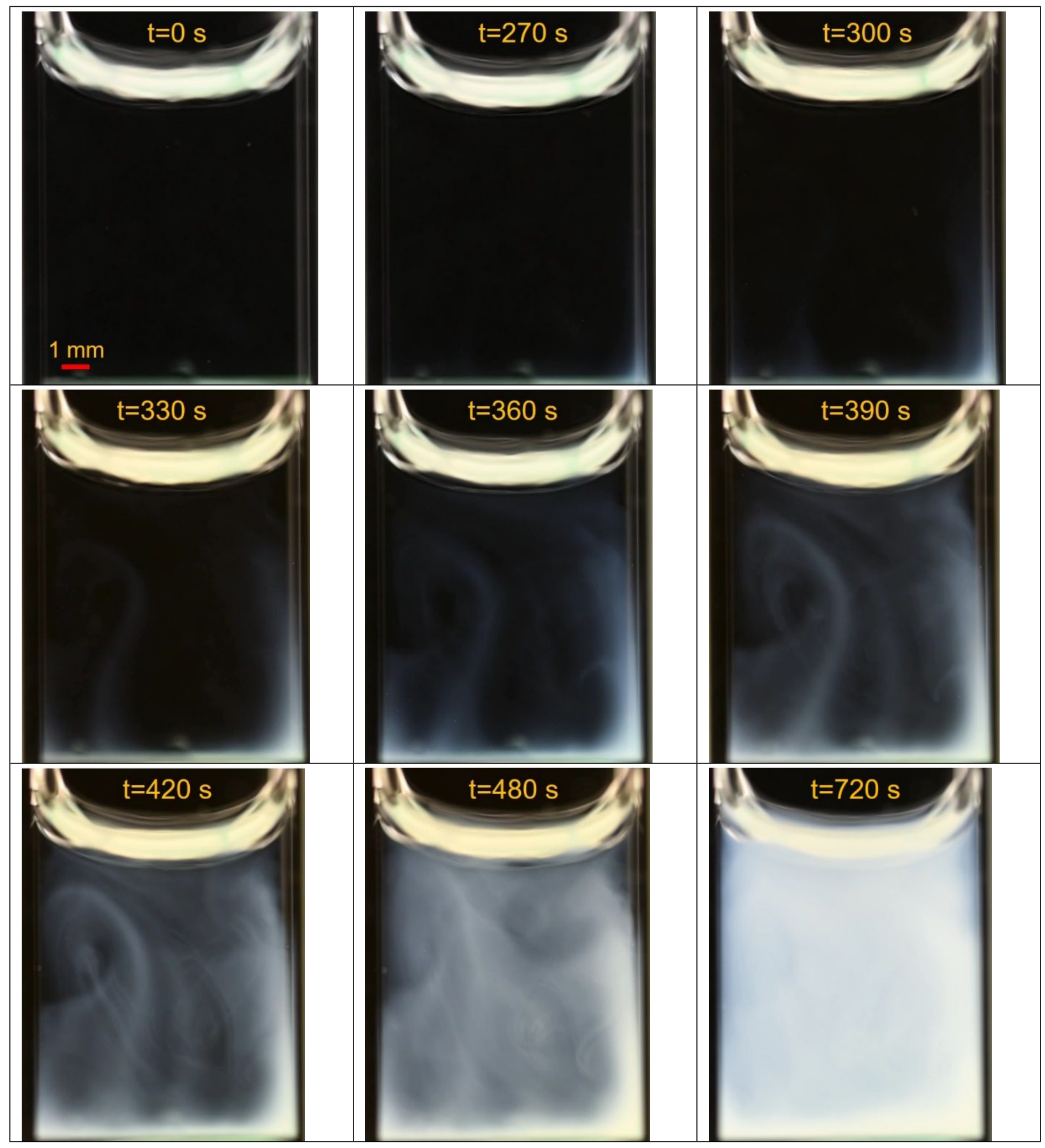

Figure S1. Acoustic wave energy absorption (turbidity) mechanism during the imposing $2.38 \mathrm{MHz}$, and $20 \mathrm{~V}$ ultrasonic actuation of the $0.2 \mathrm{wt} . \%$ microgel solution. 


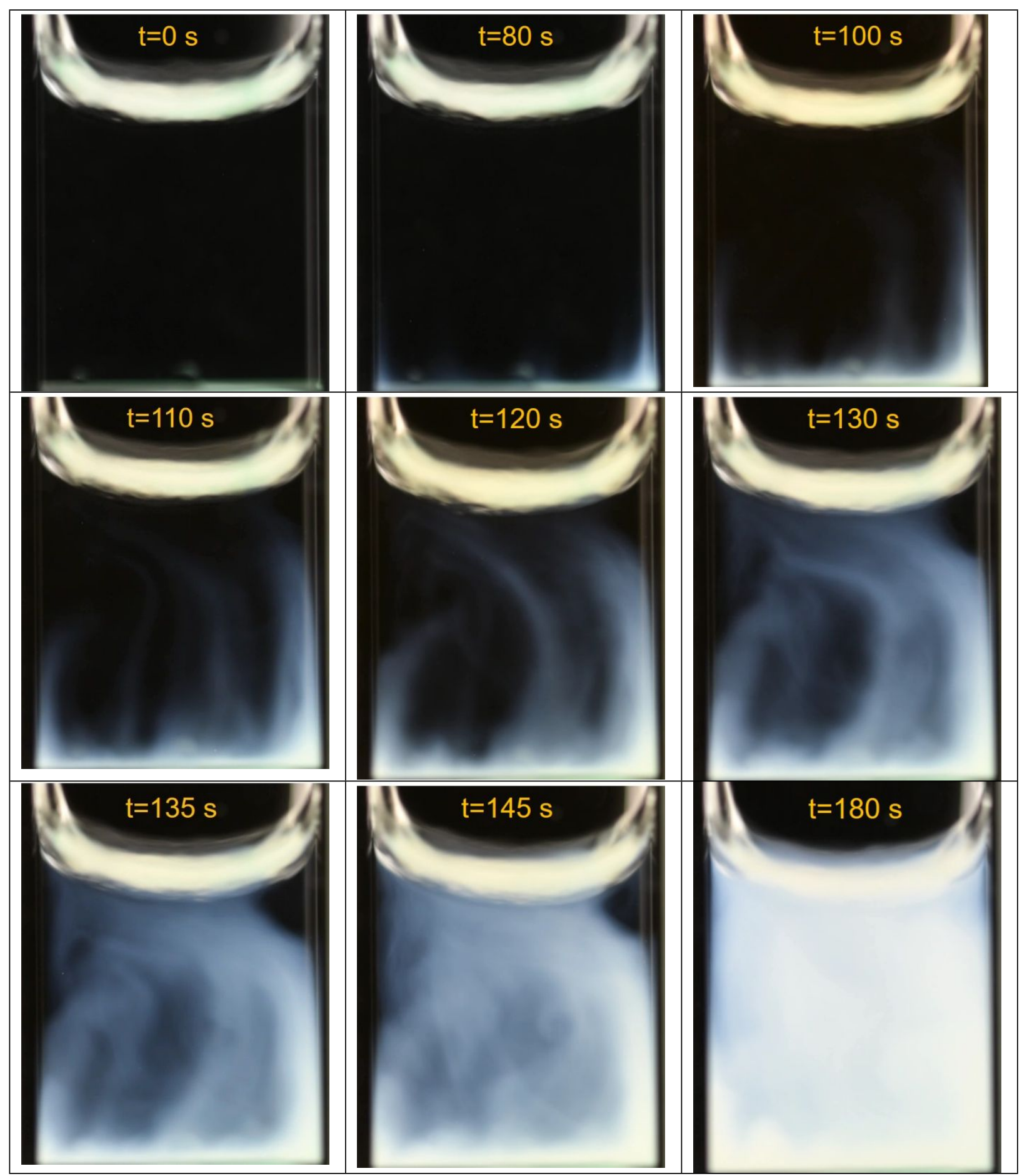

Figure S2. Acoustic wave energy absorption (turbidity) mechanism during the imposing $2.38 \mathrm{MHz}$, and $25 \mathrm{~V}$ ultrasonic actuation of the $0.2 \mathrm{wt} . \%$ microgel solution. 


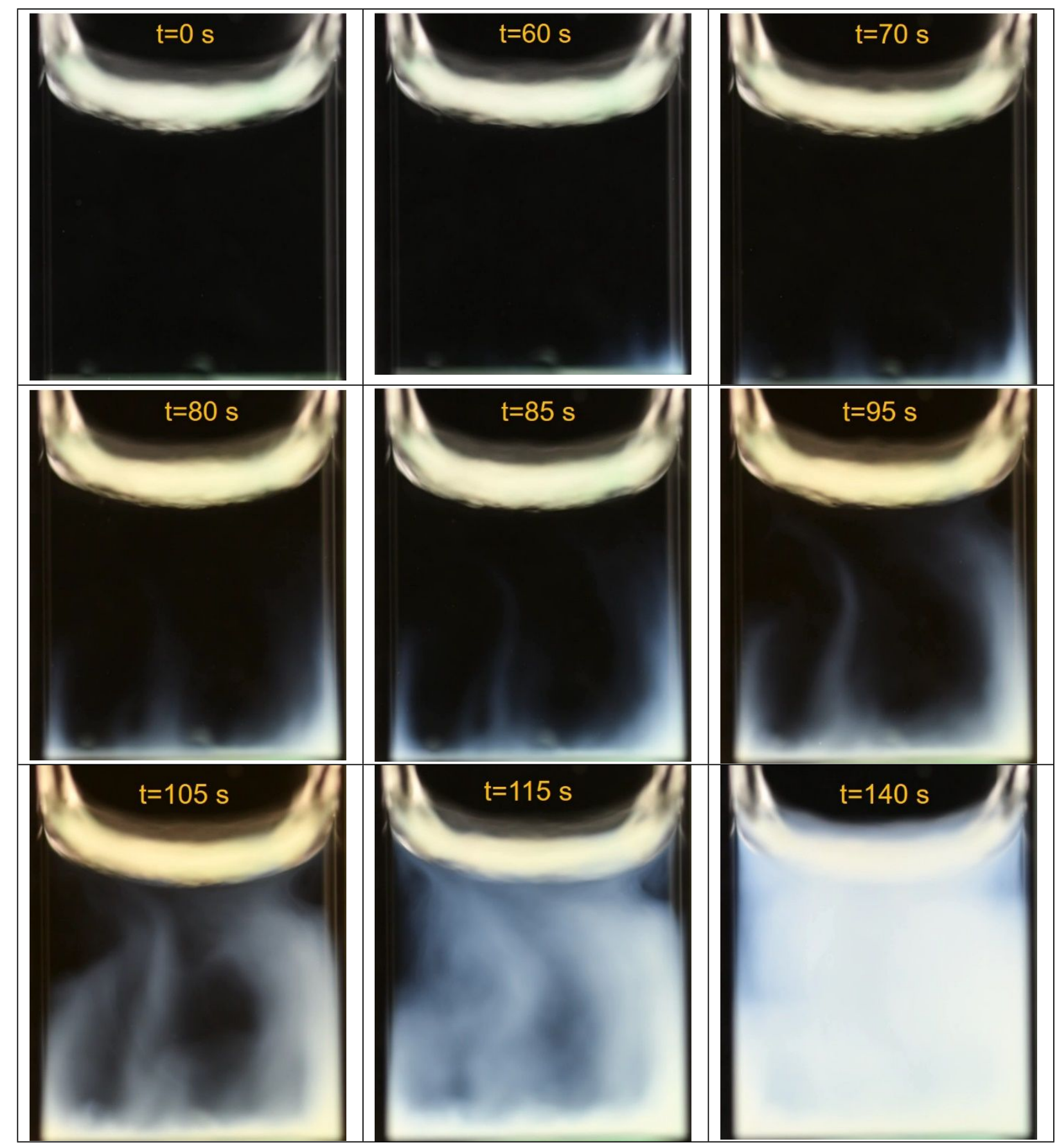

Figure S3. Acoustic wave energy absorption (turbidity) mechanism during the imposing $2.38 \mathrm{MHz}$, and $30 \mathrm{~V}$ ultrasonic actuation of the $0.2 \mathrm{wt} . \%$ microgel solution. 


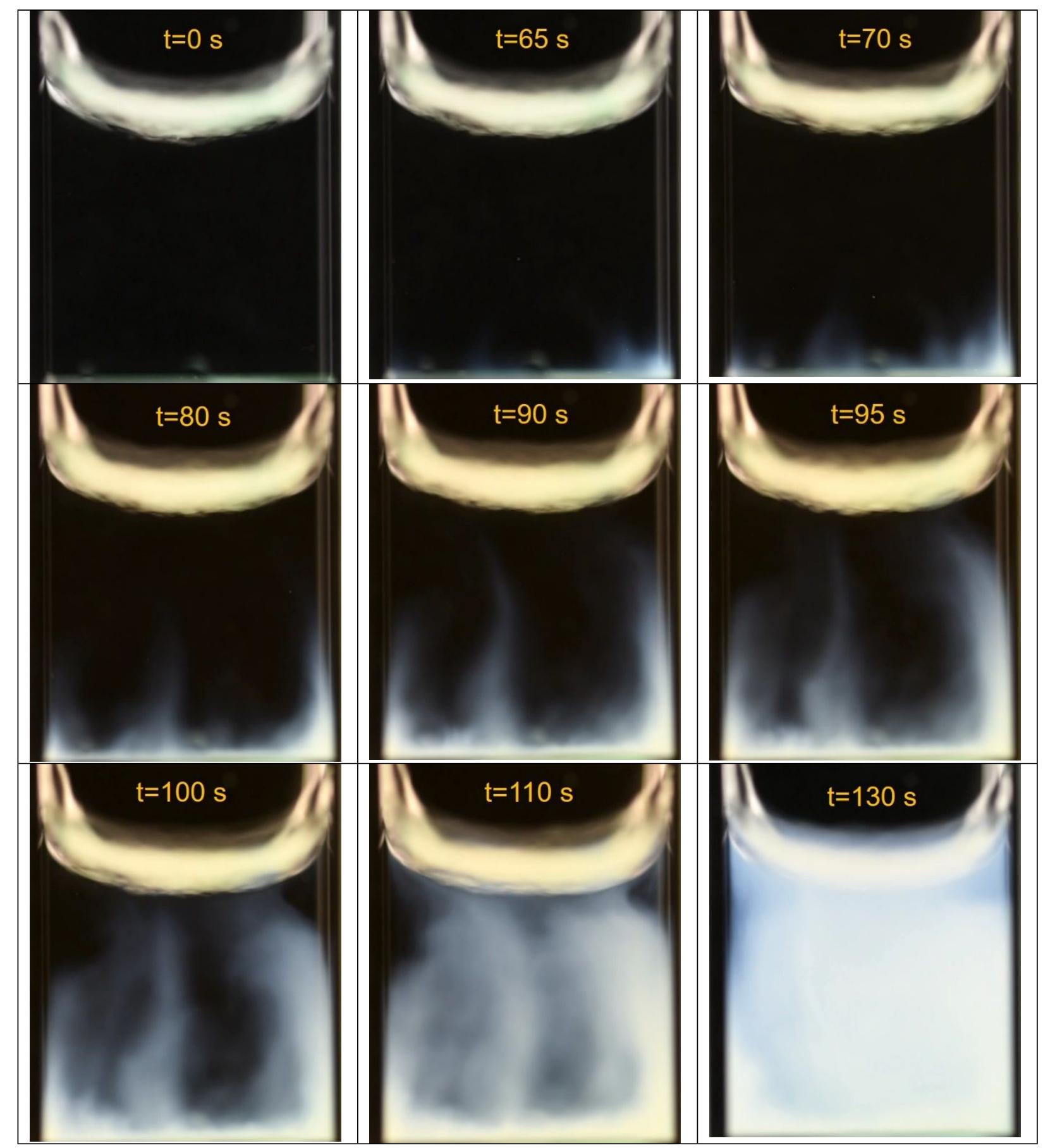

Figure S4. Acoustic wave energy absorption (turbidity) mechanism during the imposing $2.38 \mathrm{MHz}$, and $35 \mathrm{~V}$ ultrasonic actuation of the $0.2 \mathrm{wt} . \%$ microgel solution. 


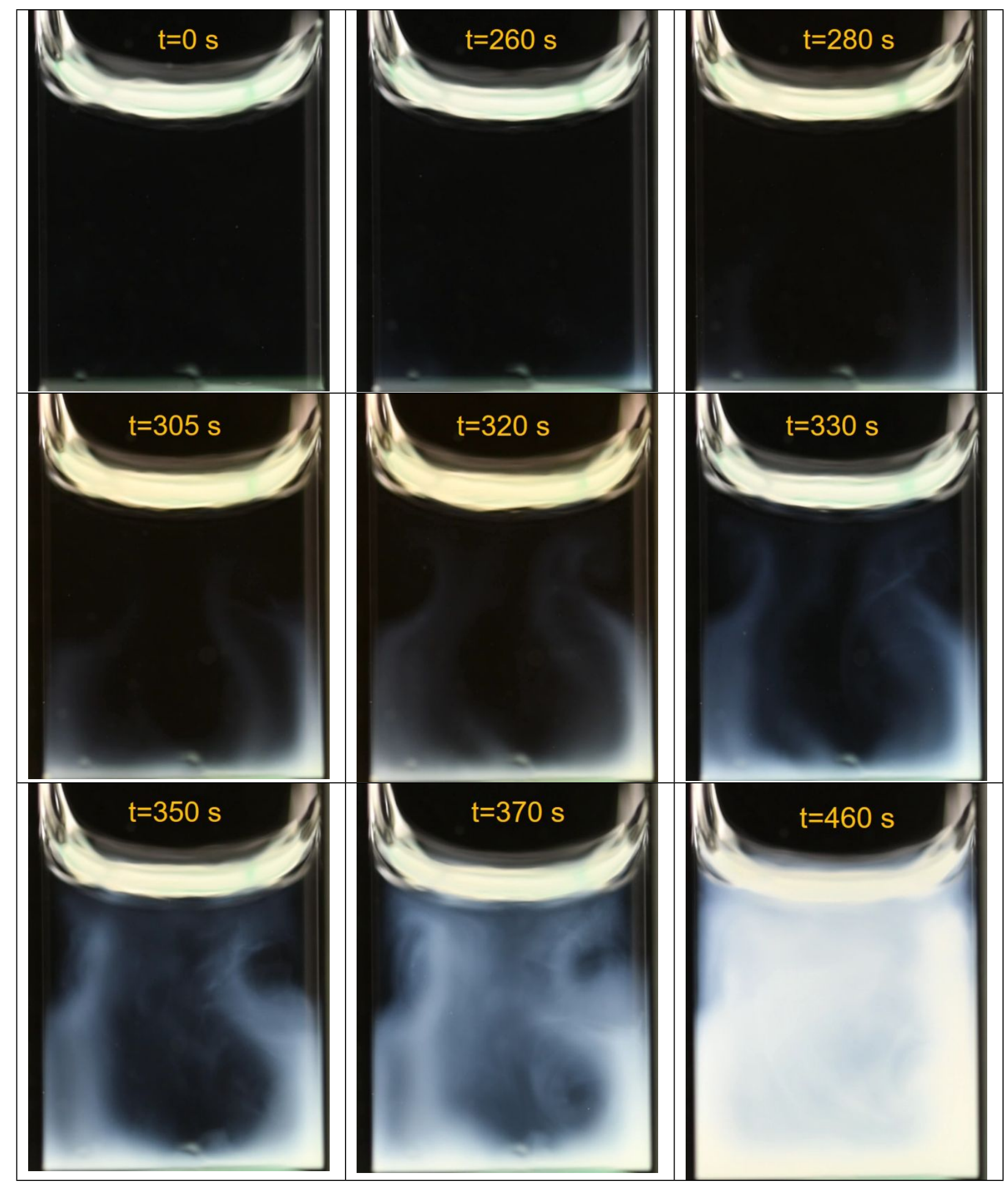

Figure S5. Acoustic wave energy absorption (turbidity) mechanism during the imposing $2.38 \mathrm{MHz}$, and $20 \mathrm{~V}$ ultrasonic actuation of the $1 \mathrm{wt} . \%$ microgel solution. 


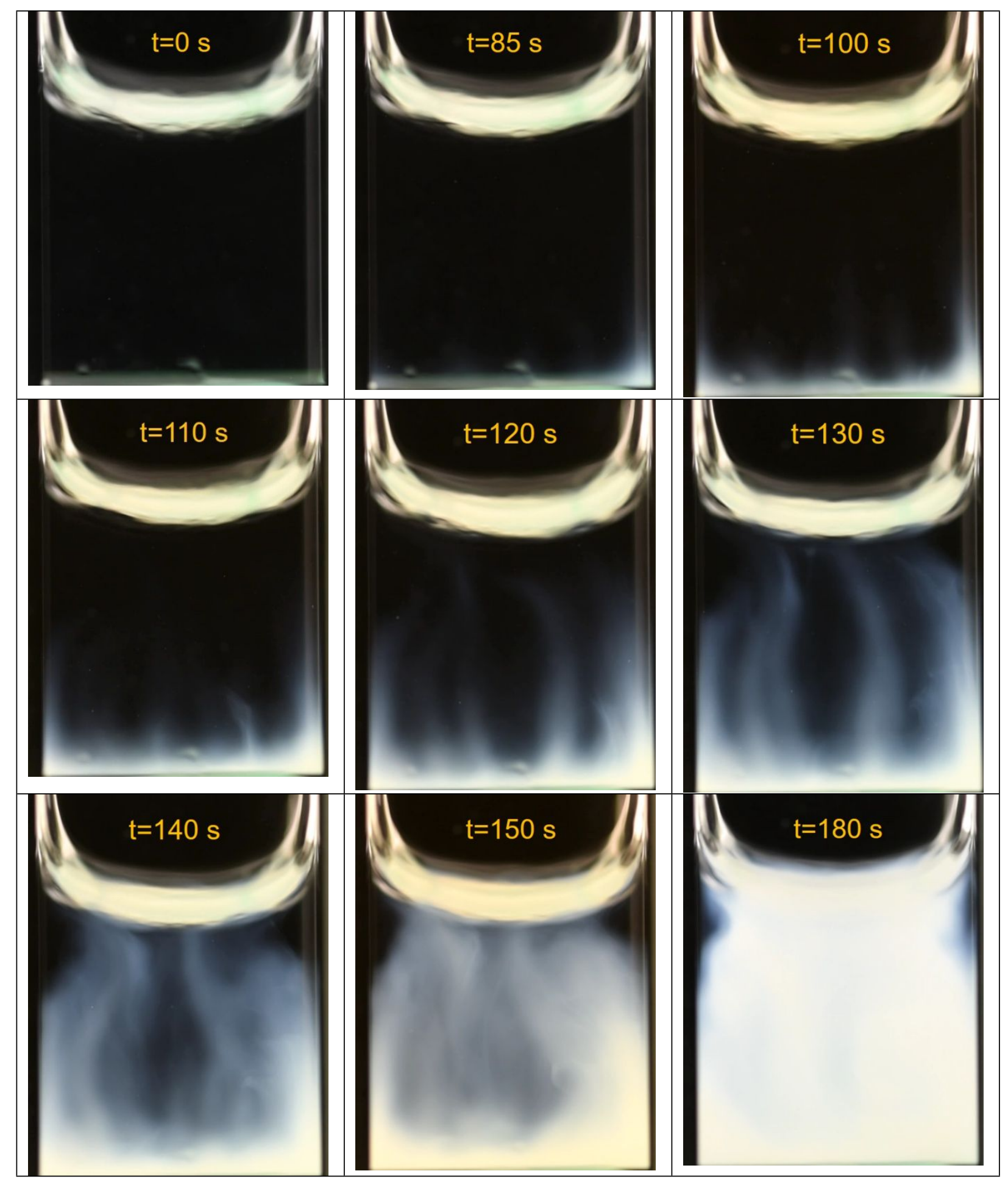

Figure S6. Acoustic wave energy absorption (turbidity) mechanism during the imposing $2.38 \mathrm{MHz}$, and $25 \mathrm{~V}$ ultrasonic actuation of the $1 \mathrm{wt} . \%$ microgel solution. 


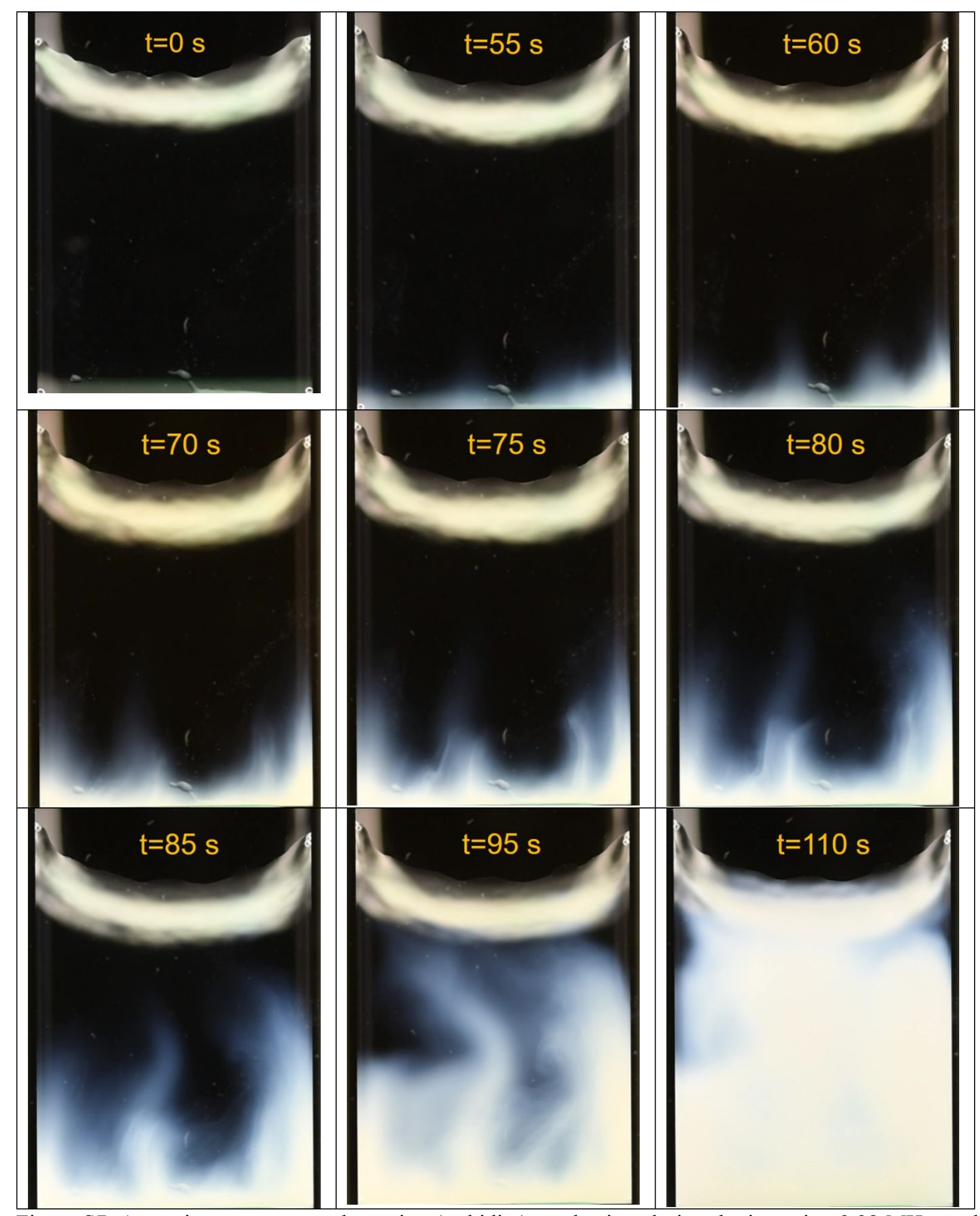

Figure S7. Acoustic wave energy absorption (turbidity) mechanism during the imposing $2.38 \mathrm{MHz}$, and $30 \mathrm{~V}$ ultrasonic actuation of the $1 \mathrm{wt} . \%$ microgel solution. 


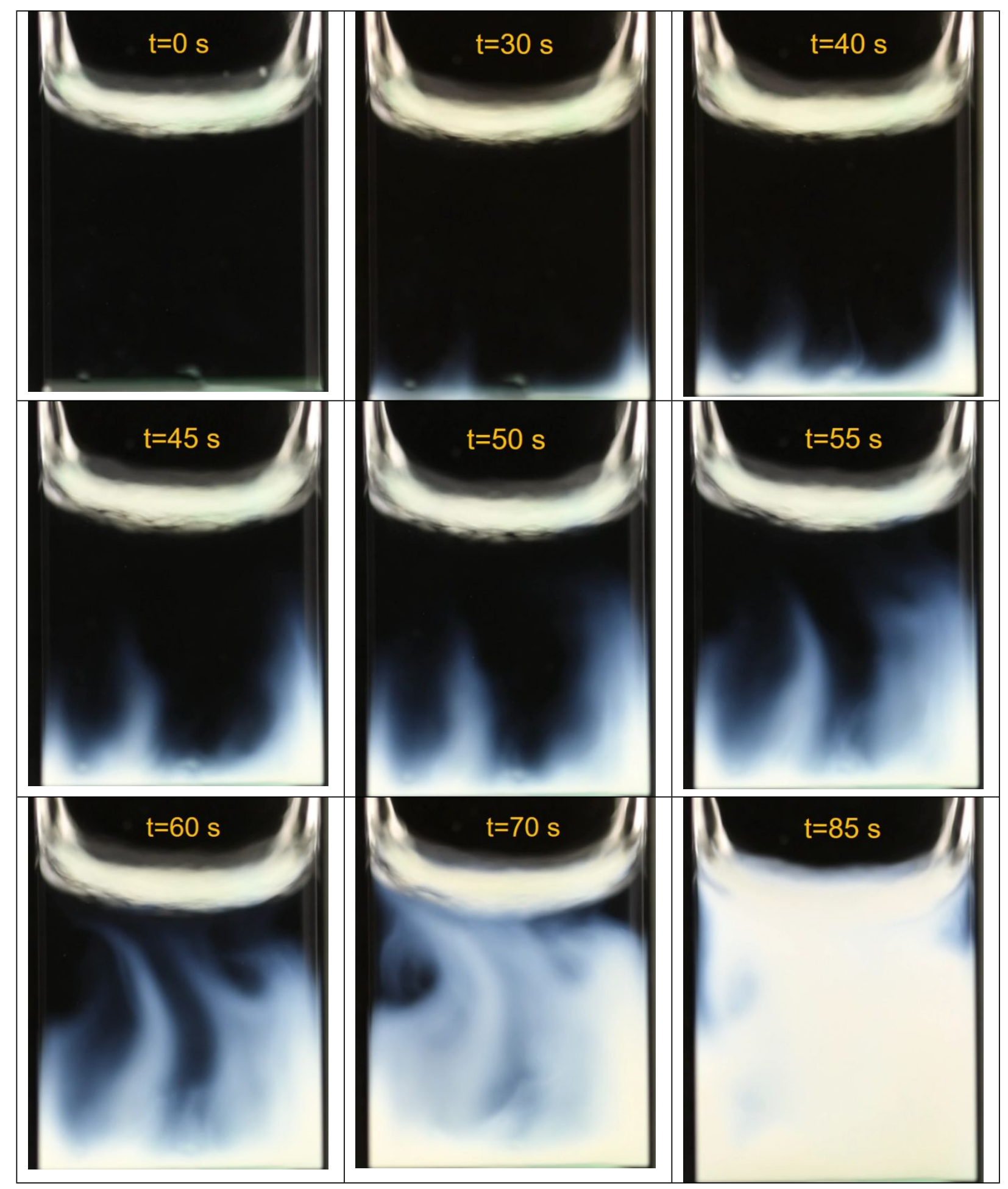

Figure S8. Acoustic wave energy absorption (turbidity) mechanism during the imposing $2.38 \mathrm{MHz}$, and $35 \mathrm{~V}$ ultrasonic actuation of the $1 \mathrm{wt} . \%$ microgel solution. 


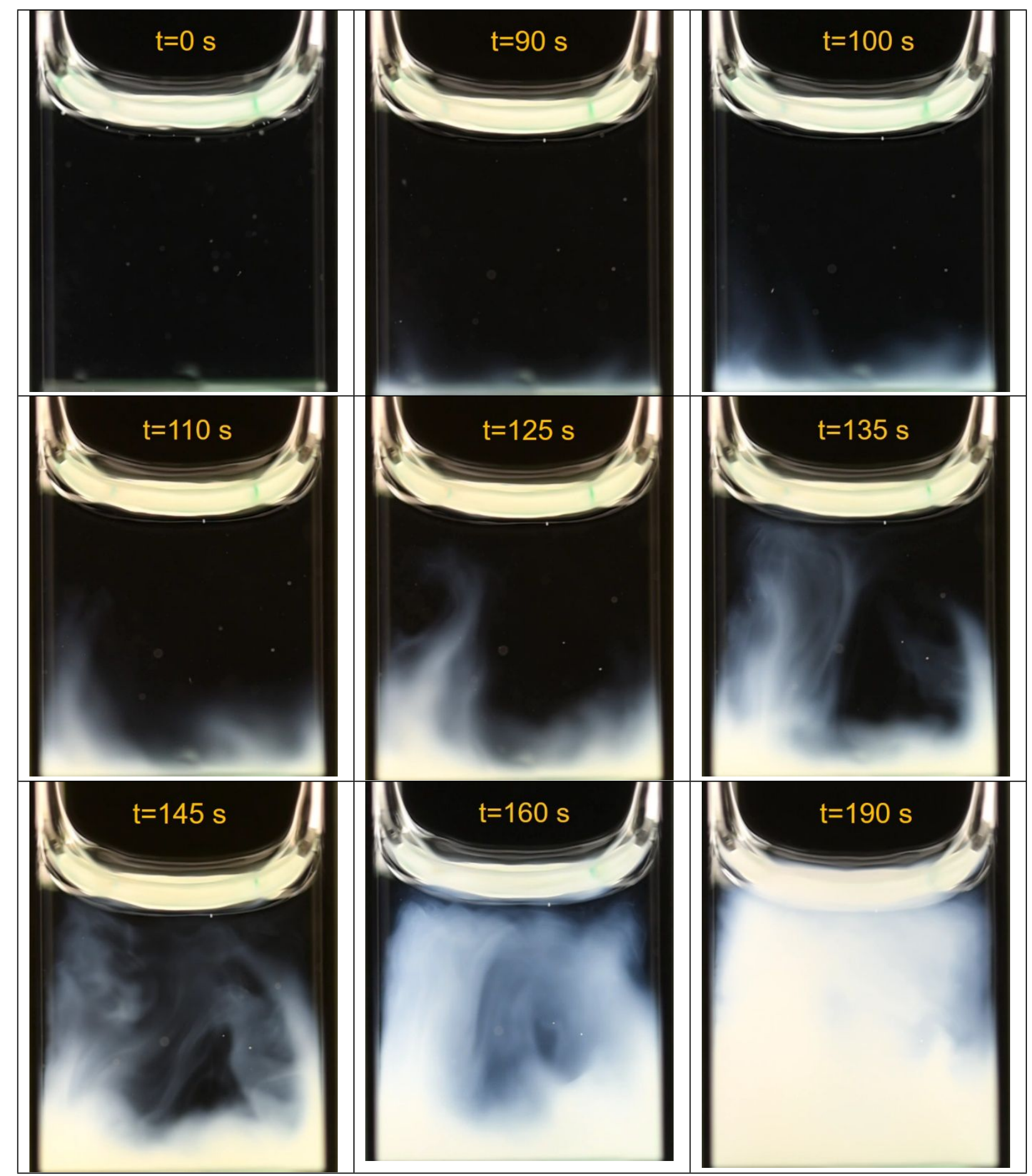

Figure S9. Acoustic wave energy absorption (turbidity) mechanism during the imposing $2.38 \mathrm{MHz}$, and $20 \mathrm{~V}$ ultrasonic actuation of the $5 \mathrm{wt} . \%$ microgel solution. 


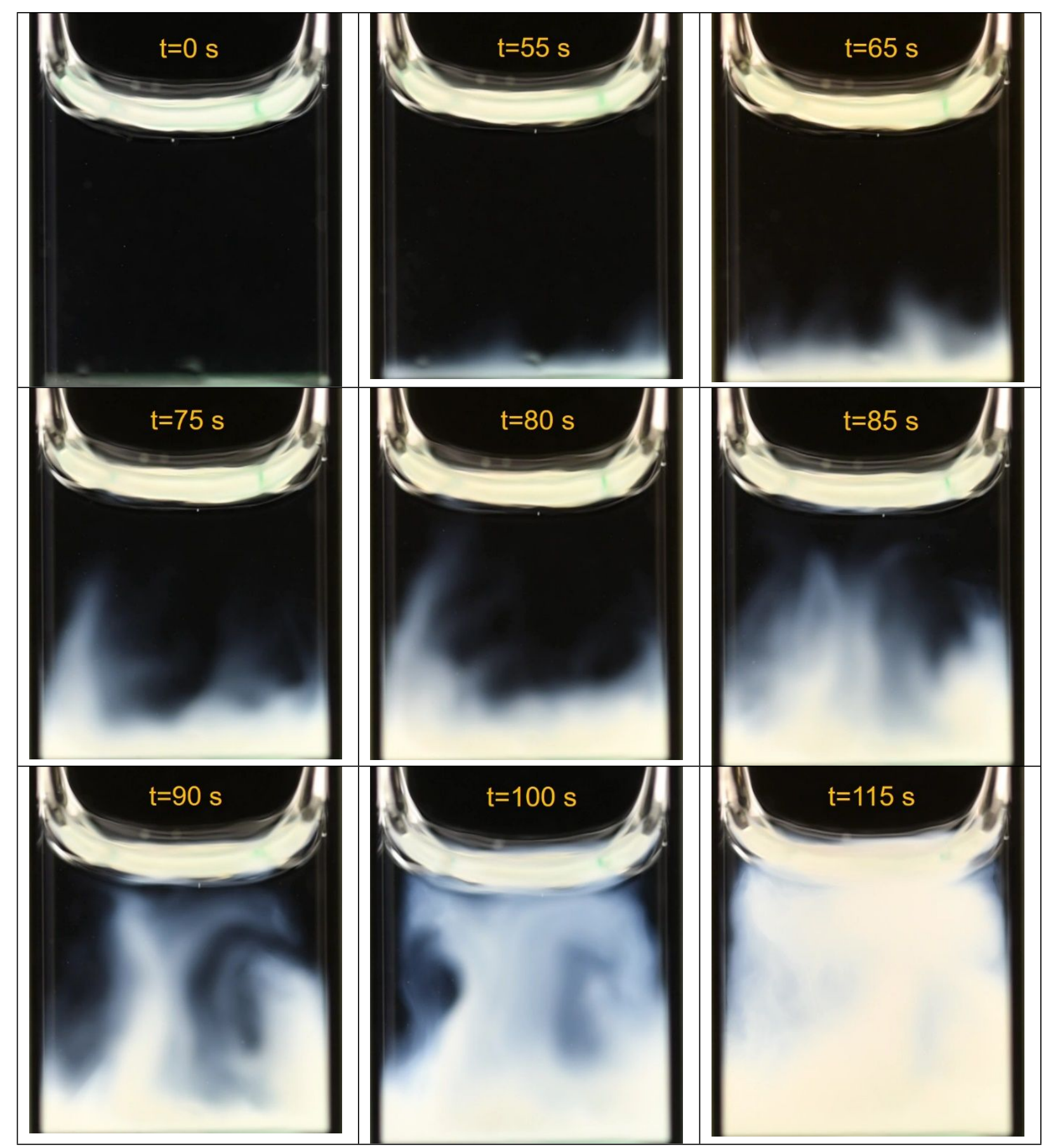

Figure S10. Acoustic wave energy absorption (turbidity) mechanism during the imposing $2.38 \mathrm{MHz}$, and $25 \mathrm{~V}$ ultrasonic actuation of the $5 \mathrm{wt} . \%$ microgel solution. 


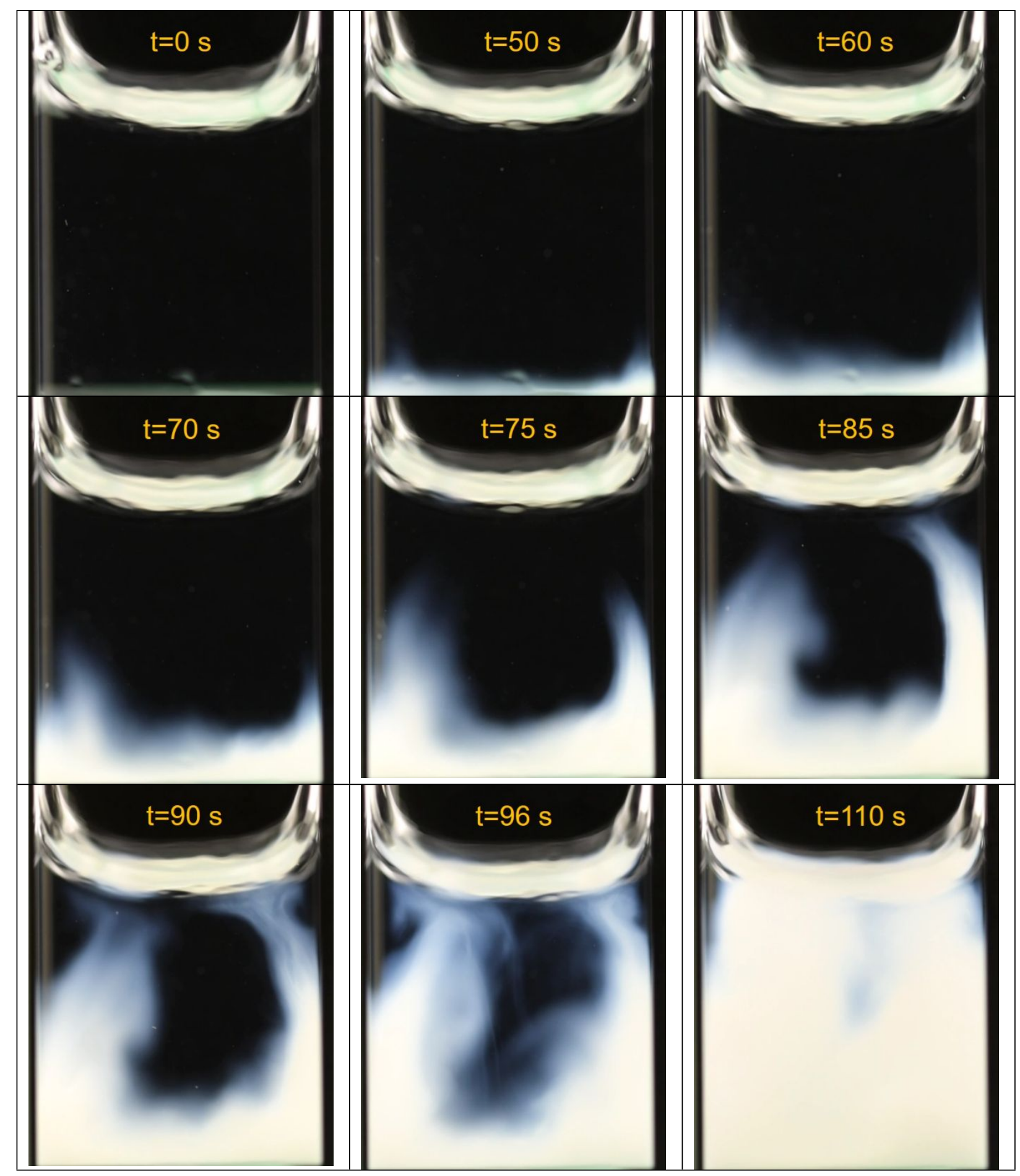

Figure S11. Acoustic wave energy absorption (turbidity) mechanism during the imposing $2.38 \mathrm{MHz}$, and $30 \mathrm{~V}$ ultrasonic actuation of the $5 \mathrm{wt} . \%$ microgel solution. 


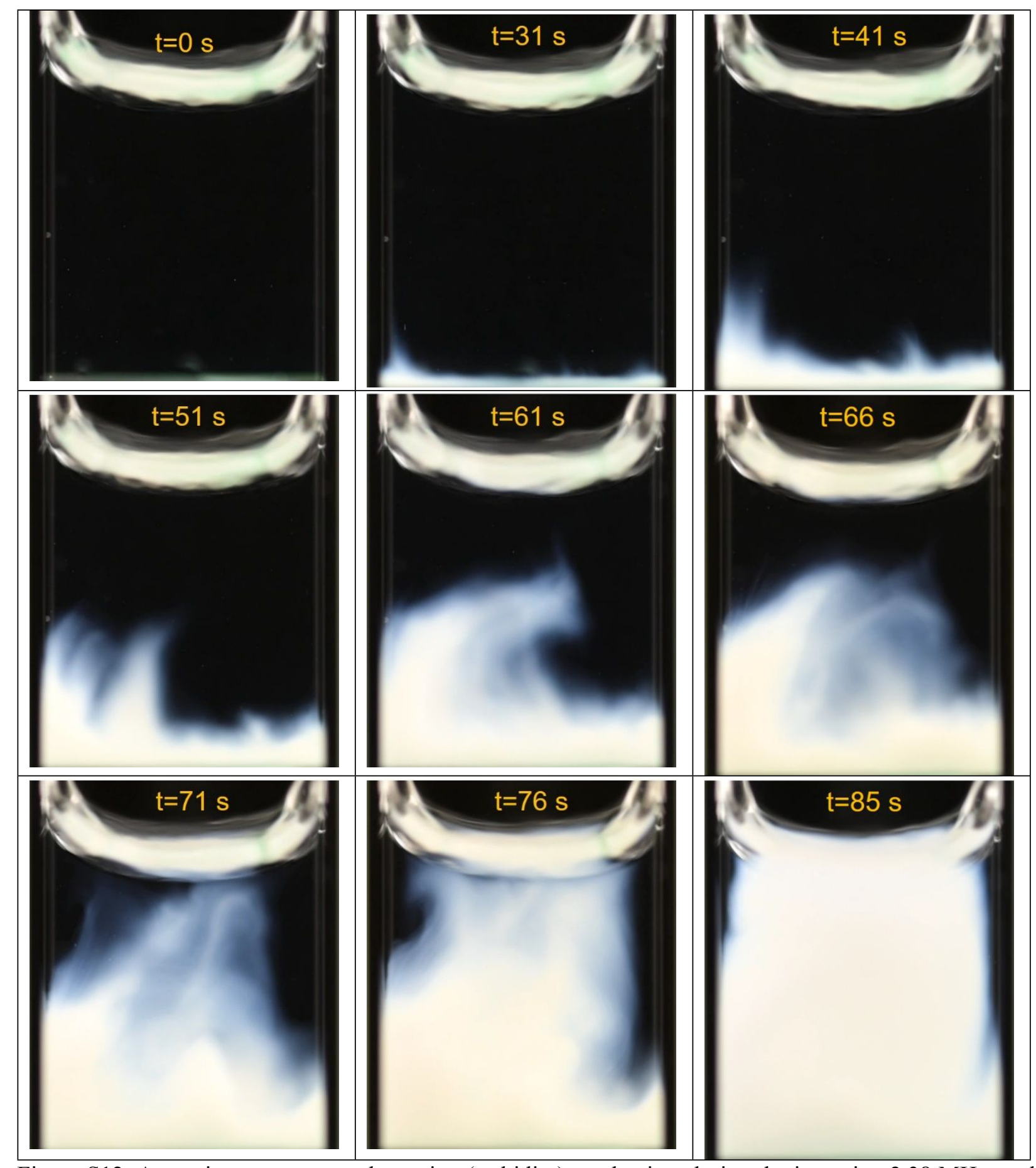

Figure S12. Acoustic wave energy absorption (turbidity) mechanism during the imposing $2.38 \mathrm{MHz}$, and $35 \mathrm{~V}$ ultrasonic actuation of the $5 \mathrm{wt} . \%$ microgel solution. 


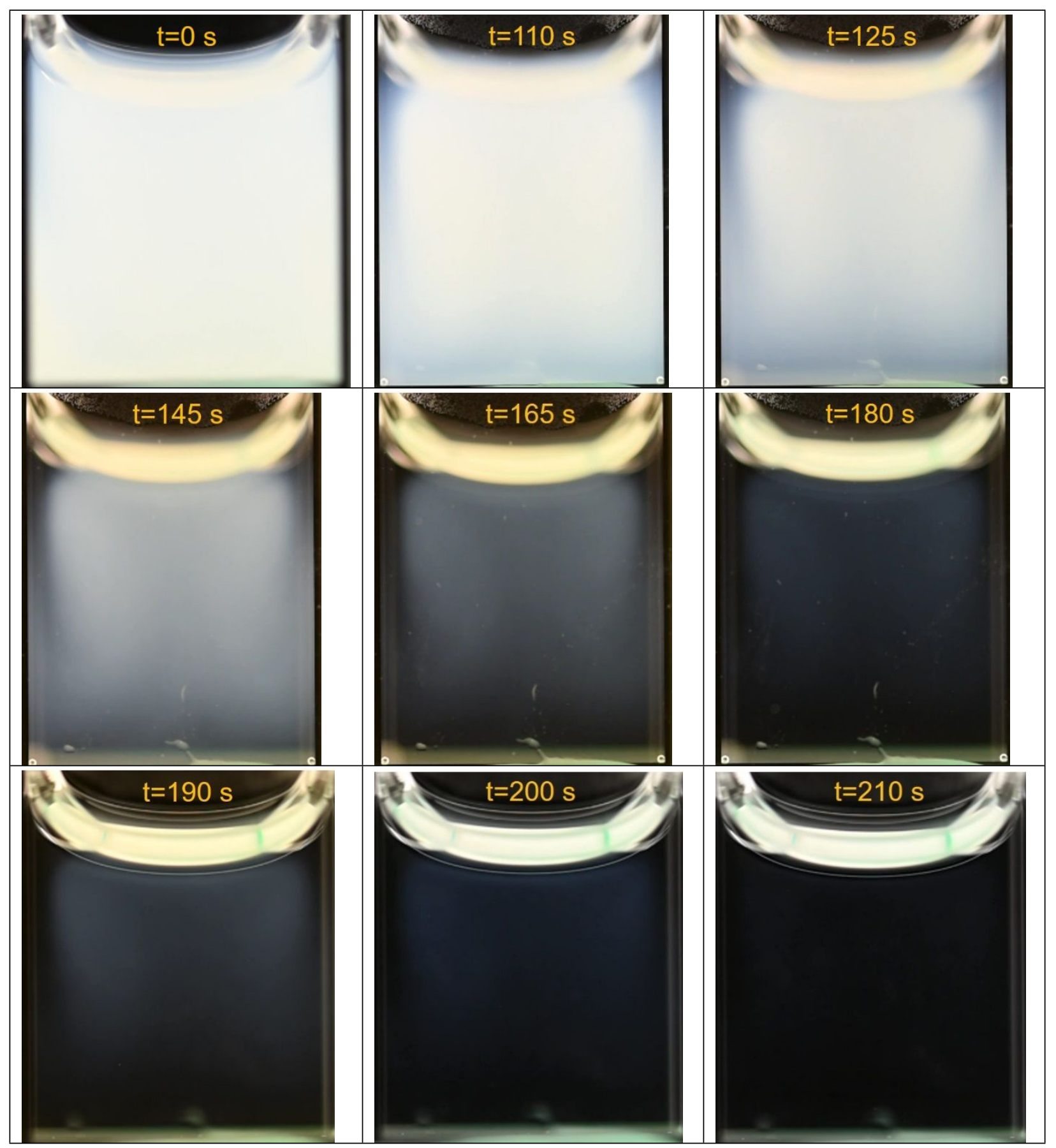

Figure S13. Reformation of the hydrogen bonds after the termination of the ultrasonic actuation of the $0.2 \mathrm{wt} . \%$ microgel solution with $2.38 \mathrm{MHz}$, and $35 \mathrm{~V}$. 


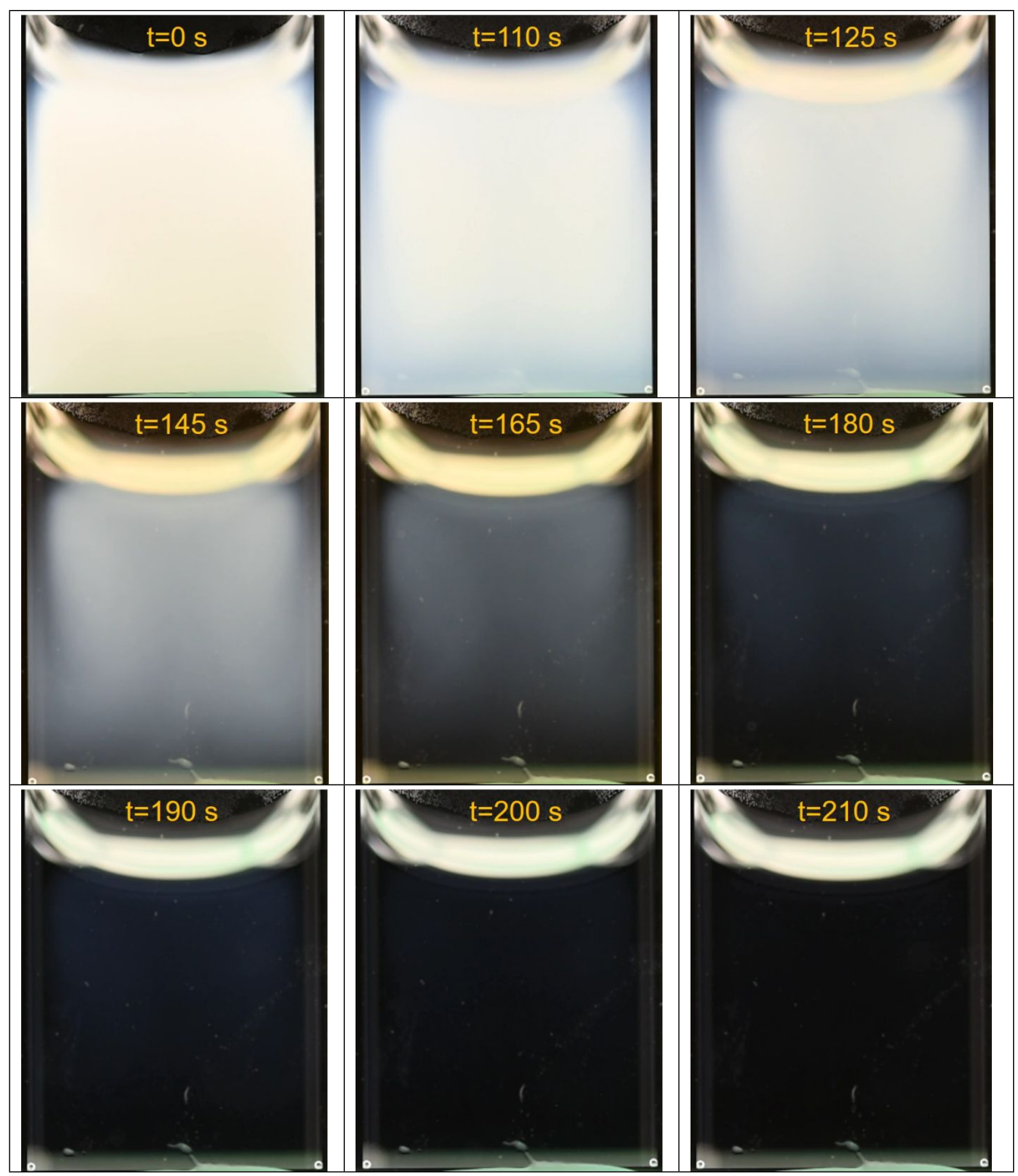

Figure S14. Reformation of the hydrogen bonds after the termination of the ultrasonic actuation of the $1 \mathrm{wt} . \%$ microgel solution with $2.38 \mathrm{MHz}$, and $35 \mathrm{~V}$. 


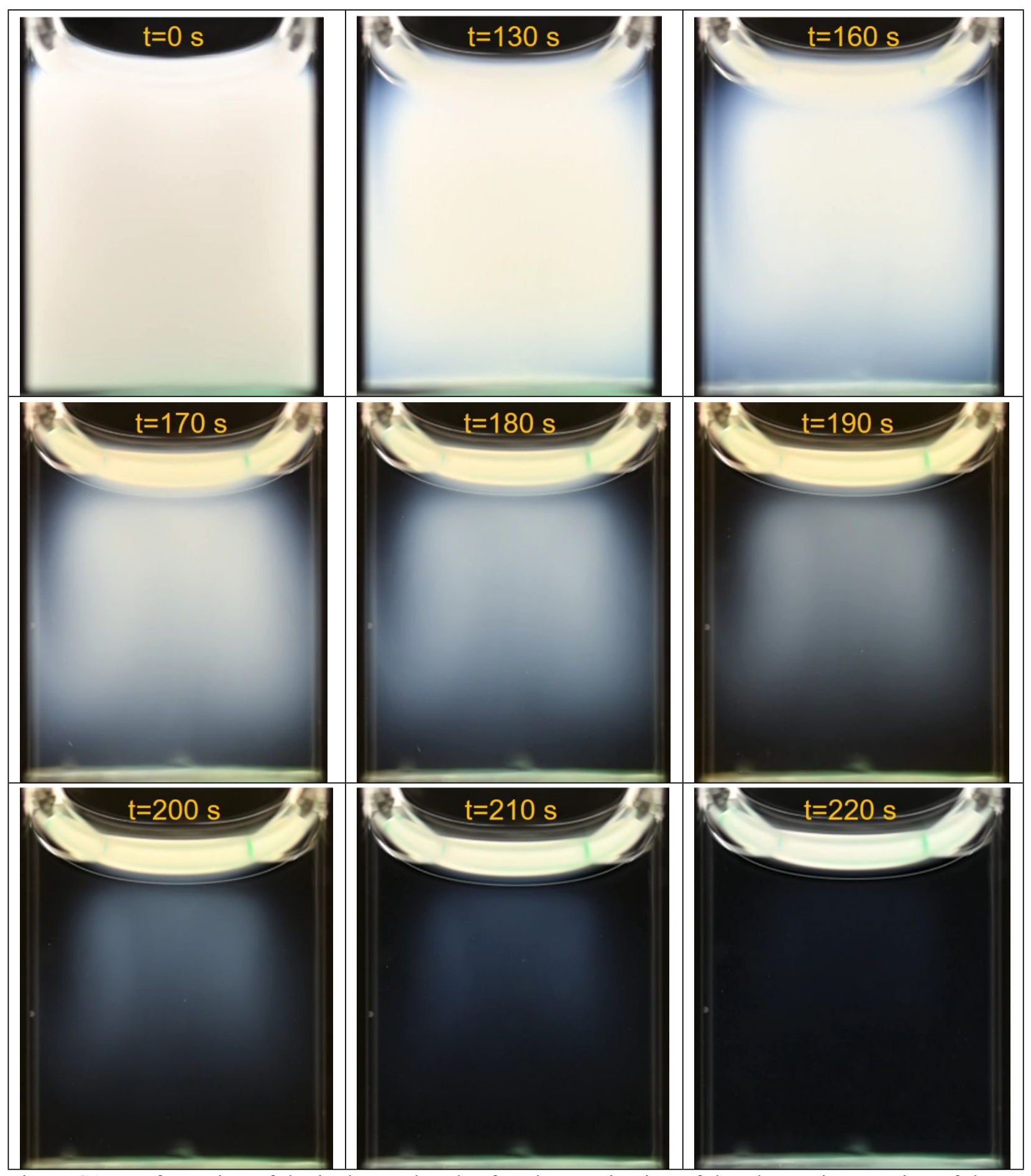

Figure S15. Reformation of the hydrogen bonds after the termination of the ultrasonic actuation of the $5 \mathrm{wt} . \%$ microgel solution with $2.38 \mathrm{MHz}$. 


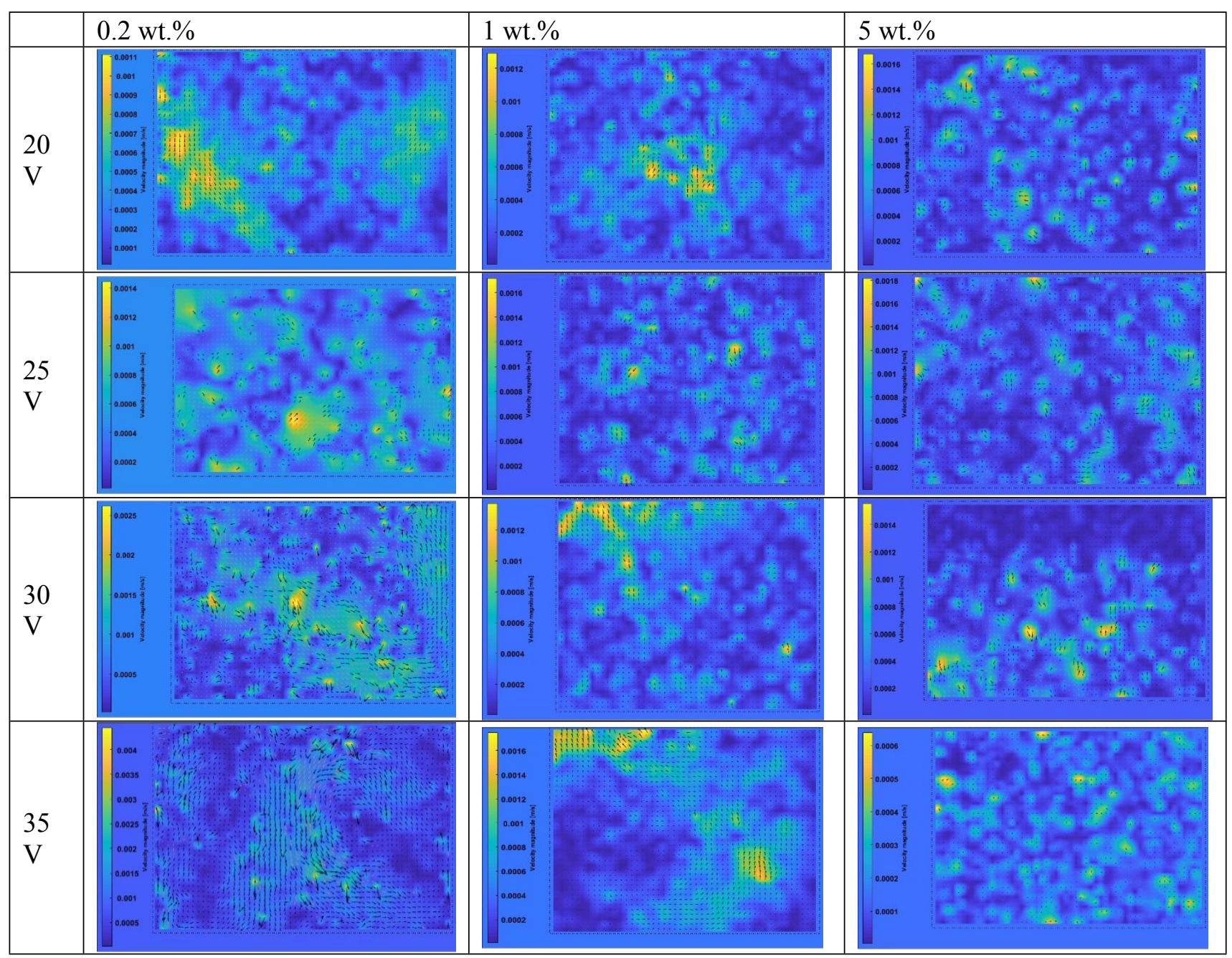

Figure S16. Acoustic streaming in PNIPAM solutions with different concentrations at four transducer voltages. 


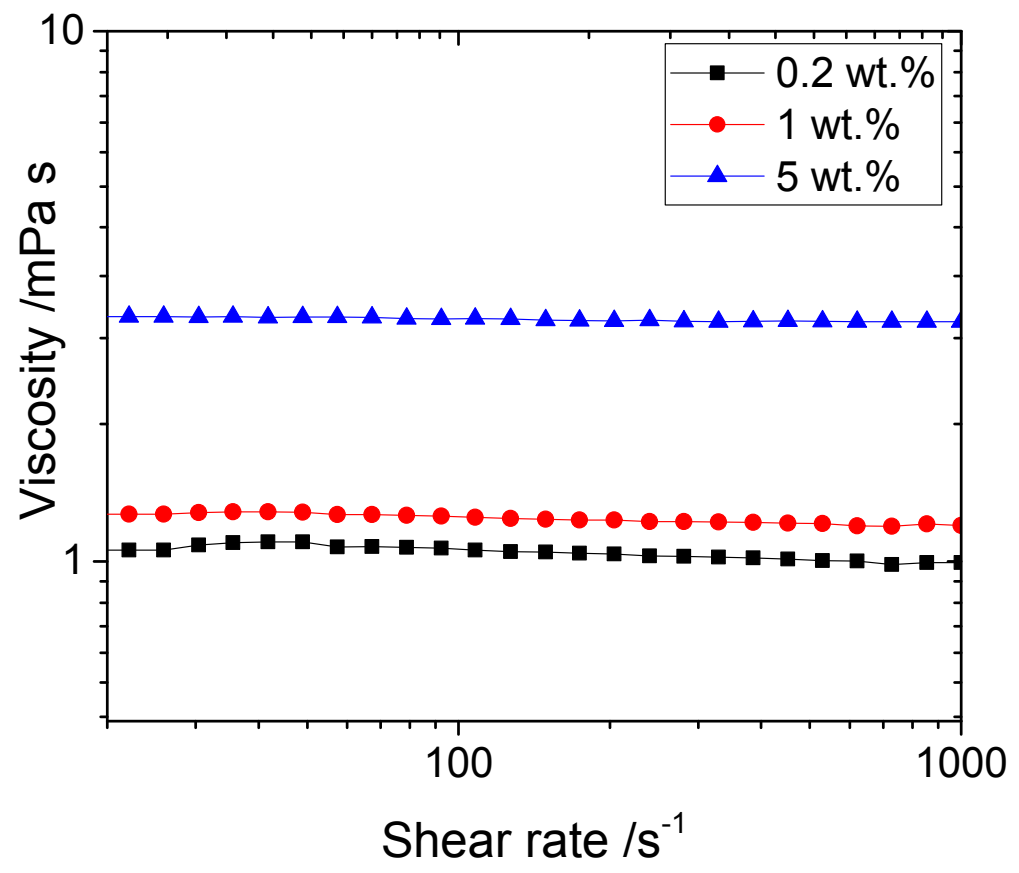

Figure S17. Viscosity of linear PNIPAM solutions with different concentrations as a function of shear rate at $25^{\circ} \mathrm{C}$. 